\title{
Influence of Women's Participation in Self-Help Groups on Their Social Networks in Tigania West Sub-County
}

\author{
Peter Maina
}

\begin{abstract}
The women participation in self-help groups has been established to have diverse effect on their social economic empowerment aspects including social networks. The self-confidence of the women members is often associated with the self-help groups through interactions with group members, exposure to a wide variety of skills and masterly of specific tasks that are undertaken within the self-help groups. The self-help groups also create and enhance social networks amongst the women. This is through the interaction with members, bonding and joint undertaking of various activities together. Through these processes the women develop social relationships amongst themselves. The women participation in self-help groups have enabled them to access credit through group lending and revolving loans amongst the members. The self-help groups create social security that enables the lending from financial institutions to the group in which they guarantee each other. The social ties amongst the group members enables the provision of the revolving loans in which the individual members are issued with loans and then thereafter other members are issued with loans after loan repayments. The study was guided by the research hypothesis that there is no statistically significant influence of women's participation in self-help groups on their social network in Tigania West Sub-County. The study used descriptive and explorative research designs. The target population was 3610 women from 250 registered self-help groups. The number of women in the 250 groups was 3610. Sample size was determined using a formula by Nassiuma (2008) to get a sample size of 150. The results of the regression indicated that participation in women self-help groups led to an increase in level of social networks due to a positive beta coefficient of 0.380 . The p-value less than 0.05 (significance level) indicates that participation in self-help groups has statistically significant influence on their social networks. This led to the rejection of the hypothesis stating that women's participation in self-help groups has no statistically significant influence on their development of social network in Tigania West Sub-County. The significance of the results can be attributed to the importance of the social networks amongst the women in self-help groups. Participation in selfhelp groups has an influence on the social network of the group members due to interaction while undertaking group activities. This enhances their bonding and consequently social networking.
\end{abstract}

Keywords: Self Help Group, Social Networks

DOI: $10.7176 /$ RHSS/10-18-01

Publication date:September $30^{\text {th }} 2020$

\section{Introduction}

The women participation in self-help groups has been established to have diverse effect on their social economic empowerment aspects including self-confidence, social networks, access to credit and income levels. The selfconfidence of the women members is often associated with the self-help groups through interactions with group members, exposure to a wide variety of skills and masterly of specific tasks that are undertaken within the selfhelp groups. The self-help groups also create and enhance social networks amongst the women (Al-Hebaish, 2012). This is through the interaction with members, bonding and joint undertaking of various activities together. Through these processes the women develop social relationships amongst themselves. The women participation in self-help groups have enabled them to access credit through group lending and revolving loans amongst the members (Aikarua, Sumari \& Maleko, 2014). The self-help groups create social security that enables the lending from financial institutions to the group in which they guarantee each other. The social ties amongst the group members enables the provision of the revolving loans in which the individual members are issued with loans and then thereafter other members are issued with loans after loan repayments (Manjunatha, 2013). The self-help groups enable different members to undertake diverse economic activities together thus improving on the economic wellbeing of the individual members. Amongst the economic activities that women engage in include small-scale trade activities such as weaving, poultry keeping, and making of detergents amongst others (Hora, 2014). The study will be guided by the following research hypothesis;

$\mathbf{H}_{0}$ : There is no statistically significant influence of women's participation in self-help groups on their social network in Tigania West Sub-County.

\section{Theoretical Review}

The study was informed by the family system theory which was established by Dr. Murray Bowen in 1966. Family systems theory proposes that family systems organize themselves to deal with challenges, individual tasks of life and developmental needs of its members. To clearly understand the family a holistic approach needs to be applied. Family interaction with others and the rules that govern them make them unique from others. How a family comes 
together defines itself and also the way others see them from outside (Brown, 1999).

Families draw boundaries between what is included in the family system and what is external to the system. These boundaries influence the movement of family members in and out. Information is regulated within the system. Some families have open while others have restricted movement in and out. What happens to one family member or what a member does influence other members. They have different patterns of rule, strategies and therefore are dynamic in nature. These dynamics ensure members are able to deal with daily challenges. According to Steinglass (1987) family is believed to have ability to maintain constituency in its organizational characteristics despite the challenges that may arise over time. The family is goal oriented with set objectives. It is able to accomplish the same goals through different routes and patterns of feedback may influence the achievement of a set goal in the family.

Family systems theory helps to understand self-help groups, their characteristics, interactions, purpose and outcomes. In self-help groups, members come together with an aim of pooling their resources together in order to deal with their socio-economic challenges and developmental needs. Self-help groups have rules that bind them together and make them function normally. Like families, groups have boundaries. The theory was applied to understand how these rules and boundaries influence the information flow within a group. Self-help groups have social and economic dynamics that determine their members' participation and empowerment. Through the help of family systems theory, the researcher established out how groups try to maintain balance between challenges and the resources as part of the dynamics in order to achieve the set objectives.

In this study family system theory was applied to understand how women participation in self-help groups influence the achievement of set objectives on socio-economic empowerment, how interaction of members influence their self-confidence and group networks. The theory helped to enlighten on how groups unity and members participation influence change income and credit access. The theory is applicable to this study because the women participating in the self-help group is analogous to the family aspects indicated in the theory. Such groups' similarity to the family enables the women to address individual and collective social economic challenges through improvement of such as self-confidence, social networks, access to credit and income levels.

\section{Empirical Literature}

For many years women have had self-governed self-help groups that enable them bring their resources together as a way of empowering themselves and developing each other sustainably. Through their networks referred as chama which means group, women form very strong system of network that hastens development. As women participate in these chamas, they empower each other and improve on their social economic livelihood. Women in self-help groups establish networks of people who share common interests. During their weekly and monthly meetings members tend to exchange ideas and contacts. This improves their individual relationships with others (Mok, Cheung \& Cheung, 2008).

Lutter (2015) states that women tend to have few connections, which may be a disadvantage, particularly to those who are in business. This is because for their business to success they need to have networks. With few connections the chances of success in entrepreneurship is hampered. Social networks are key among women who are involved in small business. According to Peltier and Naidu (2012) women entrepreneurs get frequent advices from members of their families and close friends during the business initial stages. These networks change with expansion in business and chances of succeeding are very high. Chowdhury and Amin (2011) state, women develop strong ties through socializing and end up succeeding in business start-ups. Social network can be measured with the participation of family members in the business plan. When women access money and have its control, they also require proper networks as well as empowerment strategies failure to which the consequence was a transfer of household debt and subsistence on to women leading to more complicated results, instead of improving their livelihood (Orso \& Fabrizi, 2015).

In Pakistan women participation in social economic activities has proved to lower the poverty levels of the society and raising the economic status. With globalization effects, women's social networks are improved leading to a continuous agitation for reforms in trade for the benefit of both gender (Zakaria \& Fida, 2012). Women make effort in building their own capacity by participating in self-help groups to address the socio-economic challenges facing them. They exchange ideas on existing partners who can collaborate with women groups to address various issues. This creates awareness, hence improving their social networks for their own social economic empowerment (Irshad \& Bhat, 2015). Operations of women self-help groups are normally strengthened as leaders of these groups collaborate with the local NGOs, development agencies, faith-based organizations, the government and other local groups such as CBOs (Community Based Organizations). When they work together with these development partners, the groups' social networks improve and members can benefit through trainings on issues like group management, entrepreneurship skills and dynamics leading to self-reliance of members (Akudugu and Rathinam, 2014).

In Bengal, India, Subhadip (2016) undertook a study that examined the influence of social economic empowerment through self-help groups. The women participation in self-help groups was established to be socially 
empowering in nature. The women participation in the self-help groups led to the undertaking of common social and economic activities leading to a wider social circle from the women group members. This view was further shared by Salvi (2019) in a study based in India. The study noted that amongst the activities that women need to undertake in their self-help included making detergents for sale. These activities also led to social bonding aspects. The participation in the self-help groups led to development of the social networks. These results were further consistent with those of (Kadam \& Vidya, 2017) in a study undertaken focusing on self-help groups in Kadur city, in India.

The role of the participation of women on the social economic empowerment in Tigania west sub county has not been explored by other studies hence creating a contextual gap to be filled by the study. The information on social networks and participation of women in self-help groups is readily available across the globe. However, there is need to establish how social networks operate within the self-help groups in Tigania West Sub-County. The study aim was to find out the various networks women form as they participate in self-help groups in Tigania West Sub-county. The study sought to find out the influence of social networks on women socio-economic empowerment in Tigania West Sub-county. This was thus related to objective two of the study.

\section{Research Methodology}

The study used descriptive and explorative research designs. The descriptive research design was utilized for the purposes of describing the research phenomenon as it is on the ground without any manipulation of the variables. The explorative research design on the other hand was key in enabling an exploration of relationships among variables (Mugenda \& Mugenda, 2003).

Target population was all women in self-help groups in Tigania West Sub-County. The target population was 3610 women from 250 registered self-help groups. These groups had been active for a minimum of four years, and involved in social economic development activities. This was deemed to be a sufficient period of time form women to have participated in self-help groups. The number of women in the 250 groups was 3610 . Sample size was determined using a formula by Nassiuma (2008) to get a sample size of 150 .

Ten percent of the groups were utilized in the study that is 25 groups. The 25 groups were picked through use of proportionate sampling from five administrative wards in Tigania West Sub-County. Proportions of the groups in the different wards were determined and then simple random sampling was used to select the groups. The study used the lottery method of simple random sampling process to pick the individual members per group. This was achieved through listing the group members' names in pieces of papers that were then then mixed before randomly picking (without replacement) a member to participate in the study.

The researcher used semi-structured questionnaires in data collection. Structured and semi-structured questions were included in the questionnaires. The semi structured questions gave the respondent a chance to reflect on a question before responding and freely express their feelings, views, opinions and ideas. The questions were focused, direct and simple to encourage the respondent to answer faster and correctly. The structured questions asked had a list of all possible alternative answers. Participants were required to select the answer that best suits their situation to the best of their knowledge.

After data collection and cleaning up for any errors such as inaccurate marking of responses, data was systematically organized to facilitate analysis. Coding and recording for analysis was done. Analysis was carried out using Statistical Packages for Social Sciences (SPSS) version 24. Quantitative data was analyzed using descriptive statistics such as frequencies, tables and percentages. The study used simple linear regression statistics to test the influence between participation, self-confidence, social networks, change in income and credit access. The following linear regression model was utilized for the study;

$\hat{\mathrm{Y}}=\beta_{0}+\beta_{\mathrm{i}}+\dot{\varepsilon}$

where $\hat{Y}$ is the predicted values of women empowerment.

\section{Findings and Discussions}

\section{Women Participation in Self Help Groups and Social Networks}

The objective of the study was the examination of the influence of women's participation in self-help groups on their social networks in self-help women groups. The study sought to measure the level of social networking as a measure of social empowerment of women. The study sought to establish who introduced the participants to their current self-help group, their relationship with other members of the group, number of women the participants can trust from the current self-help group, benefits that the respondent has obtained from the social networks and the number of groups the respondent can work with as per time of this research. The results of the influence of the women participation in self-help groups on the social networks are presented in the following sections.

\section{Introduction to the Group}

The manner in which the members were introduced to the current self-help groups were sought. The results are as shown on Table 1. 
Table 1: Introduction to the Group

\begin{tabular}{lll}
\hline Person & Frequency & Percent \\
\hline Self & 83 & 57.3 \\
Friends & 31 & 21.4 \\
Neighbour & 24 & 16.6 \\
Relative & 4 & 2.8 \\
Husband & 4 & 1.9 \\
Total & 146 & $100 \%$ \\
\hline
\end{tabular}

The study revealed that 57.3 percent of the participants gained membership through own initiative. It was also noted that friends introduced 21.4 percent of the participants, 16.6 percent by their neighbours, 2.8 percent by relatives and 1.9c percent were introduced by their husbands. The participants introduced by friends were considered to be more socially networked than those who introduced themselves. In terms of ranking of social networking, those introduced by friends were ranked first, then neighbour second, followed by relative, husband and lastly those who introduced themselves. The results of this study that showed that most participants were introduced through their own initiative differs from that of Mahmudul and Rahman (2015) who established in their study that majority of the participants were introduced by their friends. This was after their friends benefitted from self-help group membership and thereafter introduced their friends. The study attributed these high levels of selfintroduction to the women within the study area being ambitious and seeking financial independence on their own initiative.

\section{Relationship with other Members}

In measuring the level of social networking of the participants, the study investigated the level of relationship of the participants with other members of the group. Good relationship is an indication of good social networking. Table 2 shows the results obtained.

Table 2: Relationship with other Members

\begin{tabular}{lll}
\hline Relationship & Frequency & Percent \\
\hline Very Good & 135 & 92.9 \\
Somewhat Good & 9 & 6.2 \\
Very Poor & 1 & 0.7 \\
Total & 145 & 100.0 \\
\hline
\end{tabular}

The results reveal that 92.9 percent of the participants had a very good relationship with fellow members of their group while 6.2 percent of them had somewhat good relationship with the other members. However, one woman 0.7 percent had a very poor relationship with other members of the group. On average, the study reveals that the participants had strong social networks with other members of their group. For many years' women have had self-governed self-help groups that enable them bring their resources together as a way of empowering themselves and developing each other sustainably. Through their networks referred as chama, which means group, women form very strong system of network that hastens development. These results are established to be consistent with those of Chisholm (2014) and Kasthuri (2014) who established that women participation in the self-help groups led to their financial empowerment and improvement of their social networking. This was attributed to the women in the self-help groups enabling the sharing of common interests during their periodic meetings. In this context, Chisholm (2014) noted that the women in self-help groups establish networks of people who share common interests.

\section{Trusting other Members}

The study further sought to establish the number of women the respondent can trust from the group members. This is an indicator of the level of social empowerment and the results are shown in Table 3.

\section{Table 3: Trusting other Members}

\begin{tabular}{lll}
\hline Person & Frequency & Percent \\
\hline One & 1 & 0.7 \\
Two & 8 & 5.6 \\
Three & 12 & 8.3 \\
Four & 9 & 6.3 \\
More than four & 114 & 79.2 \\
Total & 144 & 100.0 \\
\hline
\end{tabular}

The study established that 0.7 percent of the participants could only trust one person from their group, 5 percent could trust two people, and 8.3 percent could trust three people while 6.3 percent could only trust four people. However, majority of the participants 79.2 percent could trust more than four members of their group. This implied that on average, majority of the participants were socially empowered and have high level of trust to each other. This is in agreement with Brody, et al. (2016) that women empowerment enhances their trust on other 
members in terms of group management. Handling of money meant for other group members also creates trust among the members on financial decision making and this creates a sense of solidarity ensuring individual respect from other group members, family and the community at large (Das \& Bhowal, 2014). In addition, women experience an aspect of psychological self-confidence as they participate in self-help groups.

\section{Benefit of Social Networks}

The study further sought to establish the benefits that the members have gained from their social networks. The question had multiple responses and the participants could select more than one answer hence the percentage total is greater than 100 and the frequency greater than the sample size. The findings are presented in Table 4.

\section{Table 4: Various Benefits of Social Networks to Members}

\begin{tabular}{lll}
\hline Benefit & Frequency & Percent \\
\hline Financial support & 118 & 81.4 \\
Training on capacity building & 65 & 44.8 \\
Material support & 58 & 40.0 \\
Information sharing & 58 & 40.0 \\
Moral support & 40 & 27.6 \\
\hline
\end{tabular}

The findings reveals that majority 81.4 percent of the participants were able to obtain financial support from their social networks and 44.8 percent got training from their social networks. It was also established that 40.0 percent of the participants got material support and an equivalent proportion 40.0 percent was able to share information in their social networks. The support was in kind. The study further revealed that through social networks, 27.6 percent of the participants were able to obtain moral support. World Bank (2014) assert that an empowered woman is of beneficial to themselves and their community. This empowerment is achieved through the participation in women groups. As women participate in self-help groups, they are empowered with technical and entrepreneurial skills through trainings. They interact and share their experiences (Das, 2012).

\section{Groups that Participants is Able to Work with}

The study further sought to establish whether the number of groups a respondent works with is an indicator of the level of social empowerment. Figure 8 shows the findings with regard to this aspect of social empowerment.

\section{Number of Groups}

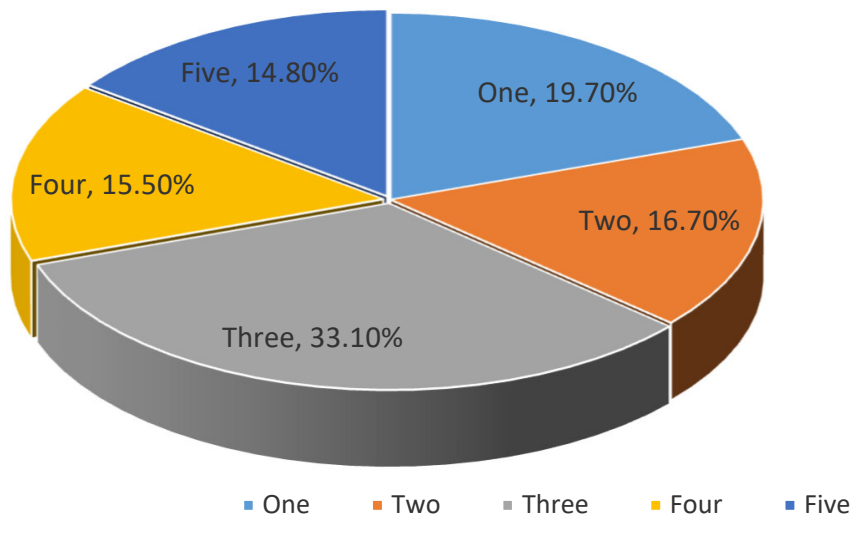

Figure 1: Number of Group

The study established that 19.7 percent of the participants they were able to work with one group while 16.9 percent indicated that they were able to work with two groups. The study established that 33.1 percent of the participants were able to work with three groups and 15.5 percent could work with four groups. This implied that majority of the participants were socially empowered for they were able to work with more than one women selfhelp group. This findings were consistent with the findings of Pillai (2017) who stated that most of the women are likely to be members of several self-help groups depending on their social network levels. The women who are socially active are members of various groups based on their activity levels in various social groups such as church, family and their localities.

\section{Hypothesis Testing}

The second hypothesis was that women's participation in self-help groups had no statistically significant influence 
on their development of social network in Tigania West Sub-County. The null hypothesis was tested using simple linear regression. The data was converted to interval data to enable linear regression analysis through data transformation process. This was achieved through summating the responses of the variables in order to turn them from ordinal based scales to continuous data in order to enable the regression analysis aspects.

Table 5: Model Coefficients ${ }^{\text {a }}$ for Social Networks

\begin{tabular}{|c|c|c|c|c|c|}
\hline \multirow[t]{2}{*}{ Model } & \multicolumn{4}{|c|}{ Unstandardized Coefficients Standardized Coefficientst } & \multirow[t]{2}{*}{ Sig. } \\
\hline & $\mathrm{B}$ & Std. Error & Beta & & \\
\hline (Constant) & 54.896 & 7.466 & & $7.353 *$ & 0.00 \\
\hline Participation & 0.380 & 0.147 & 0.757 & $2.586^{*}$ & 0.00 \\
\hline
\end{tabular}

a. Dependent Variable: Social Networks $\mathrm{P}<0.05^{*}$

The results of the regression indicated that participation in women self-help groups led to an increase in level of social networks due to a positive beta coefficient of 0.380 . The p-value less than 0.05 (significance level) indicates that participation in self-help groups has statistically significant influence on their social networks. This led to the rejection of the hypothesis stating that women's participation in self-help groups has no statistically significant influence on their development of social network in Tigania West Sub-County.

The significance of the results can be attributed to the importance of the social networks amongst the women in self-help groups. The results are similar to those of Chowdhury and Amin (2011) who established out that when women develop strong ties through socializing, they end up succeeding in business start-ups. Vasantha (2014) study further established that women participation in the self-help groups leads to the development of social networks through meetings, discussions and joint participation of activities.

\section{Conclusion of the Study}

Participation in self-help groups has an influence on the social network of the group members. This was attributable to various reasons including women interaction during group activities, gaining of trust amongst members, and development of relationship with other members. These activities have the influence of enhancing women bonding and consequently social networking.

\section{References}

[1] Aikarua, B. D., Sumari, A. G., \& Maleko, N. G. (2014). Social functionality of self-help groups in Tanzania. Journal of Business Administration and Education, 5 (2), 99-136.

[2] Akudugu, M. A., \& Rathinam U. R. (2014). Self-help as a "Livelihood Development" for rural women: Experience from India and Ghana. Journal of Economic and Sustainable Development, 5 (15), 194-201.

[3] Al-Hesbaish, S. M. (2012) The Correlation between General Self Confidence and Academic Achievement in the Oral Presentation Course: Journal of Theory and Practices Studies, 2 (1), 60- 65.

[4] Brody, C., Hoop, T. D., Vojtkova, M.,Warnock, R., Dunbar, M., Muithy, P., \& Dworkin, S. L. (2016). Can self-help group programs improve women's empowerment? A systematic review. Journal of Development Effectiveness, 1 (1), 1-26.

[5] Brown, J. (1999) Bowen Family Systems Theory and Practice: Illustration and Critique. Australian and New Zealand Journal of Family Therapy, 20 (2), 94-103.

[6] Chisholm, K. (2014). An Assessment of Empowerment in Women's Self Help Groups in Rural Rwanda. Unpublished Thesis: Deakin University.

[7] Chowdhury, M. S. , \& Amin, M. N.(2011). The effects of human social, and financial capital on the woman entrepreneurship venturing in Bangladesh. International Journal of Business and Economics Perspectives, 6 (1) 138-149.

[8] Das, S. K., \& Bhowal, A. (2014). Quality Assessment of Self Help Groups on Stakeholders Perspectives: A Psychometrics Analysis. International Journal of Economics, Finance and Management Sciences, 1(6), 347-366

[9] Das, S. K. (2012). Best practices of self-help groups and women empowerment: A case of Barak valley of Assam. Far East Journal of Psychology and Business, 7 (3), 29-51.

[10] Hora, E. A. (2014). Factors that affect women participation in leadership and decision making positions. Asian Journal of Humanity, Art and Literature, 1 (2), 97-117.

[11] Irshad, I. A. \& Bhat, A. A. (2015).The vitality and role of self-help groups (SHGs) in women upliftment: Special reference to Kashmir. International Journal of Research-Granthalayah, 3 (8), 105-110.

[12] Kadam, R. N., \& Vidya, K. (2017). Self Help Groups for Women Empowerment: A Study in Kadur City of Karnataka. International Journal of Engineering Technology Science and Research, 4(12), 1002-1006.

[13] Lutter, M. (2015). Do women suffer from network closure? The moderating effect of social capital on gender inequality in a project-based labor market 1929-2010. American Sociological Review, 80 (2), 329-358.

[14] Mahmudul, M. H. \& Mizan, R. (2015). Self-help groups in Bangladesh: Review of Enterprise and Management Studies, 2 (1), 62-78. 
[15] Manjunatha, S., (2013). The role of women self-help groups in rural development of Karnataka state, India. International Research Journal of Social Sciences, 2 (9), 23-25.

[16] Mok, B., Cheung, Y.W., \& Cheung, .T.S. (2008). Empowerment effect of self-help group participation in Chinese context. Journal of Social Services Research, 32 (3), 87-108.

[17] Mugenda, O. M., \& Mugenda, A.G.(2003). Research methods: Quantitative and qualitative approaches. Act Press, Nairobi, Kenya.

[18] Nassiuma, K. (2008). Survey Sampling: Theory and Methods. University Press, Nairobi, Kenya.

[19] Orso, C., \& Fabrizi, E.(2015). The development of women's empowerment in Bangladesh: The role of partner's attitudes and participation in microcredit programmes. The Journal of Development Studies, 52 (6), 895-912.

[20] Peltier, J.W. \& Naidu, G. M. (2012). Social networks across the SME organizational Life cycle. Journal of Small Business and Enterprise Development,19 (1) 74-91.

[21] Pillai, D. (2017). Mediating Role Of Self Help Groups For Stimulating Rural Financial Intermediation In India. Journal of Internet Banking and Commerce, 22 (7) 1-11.

[22] Quasba G. N. , Sharma, K., \& Tanki, A. A. (2016). Impact of women self-help groups on Sustainable Development in Jammu and Kashmir (A case study of Basohli), International Research Journal of Interdisciplinary \& Multidisciplinary Studies, 11 (111), 21-28.

[23] Rahman, A. (2013) Women's Empowerment: Concept and beyond, Journal of Human Social Science Sociology and Culture, 13 (6), 1-6.

[24] Salvi, N. K. (2019). Empowerment Through Self-Help Groups. Shodhshauryam, International Scientific Refereed Research Journal, 2(1), 69-73.

[25] Sarania, R. (2015). Impact of Self-Help Groups on Economic Empowerment of Women in Assam. International Research Journal of Interdisciplinary \& Multidisciplinary Studies, 1(1), 148-159.

[26] Saravana, M. (2016). The impact of self-help groups on socio-economic development of rural household women in Nadu: A case study. International Journal of Research-Granthaalayan, 4 (7), 22-31.

[27] Steinglass, P. (1987). Handbook of Developmental Psychopathology. Springer Science and Business Media, New York.

[28] Subhadip, P. A. L. (2016). Social and Economic Empowerment of Rural Women through Self Help Groups (SHGS): A Case Study in West Bengal, India. International Journal of Agriculture Sciences, 8(32), 16731676

[29] Treng, S. (2015). Self Help Groups ( SHGs ) as a Tool of Socioeconomic Development of Rural People in the Mekong Region provinces of Cambodia ). Journal of Business and Management, 9, 107-112.

[30] Vasantha, S. (2014). Challenges of Self Help Group Members Towards Income Generation Activity. International Journal of Accounting and Financial Management Research, 4(2), 1-6.

[31] World Bank Group. (2014). Voice and agency empowering women and girls for shared responsibility. Washington D.C. Britain.

[32] Zakaria, M., \& Fida, B.A. (2012). Effect of globalization on women in Pakistan, Humonomics, Emarald Insight 281 (3), 180-186. 